\title{
La articulación semiológica del concepto, el símbolo y la metáfora en el $\$ 59$ de la Kritik der Urteilskraft
}

Marcela Brito Valenzuela Estudiante del Programa de Doctorado en Filosofía, Pontificia Universidad Católica de Valparaíso, Chile

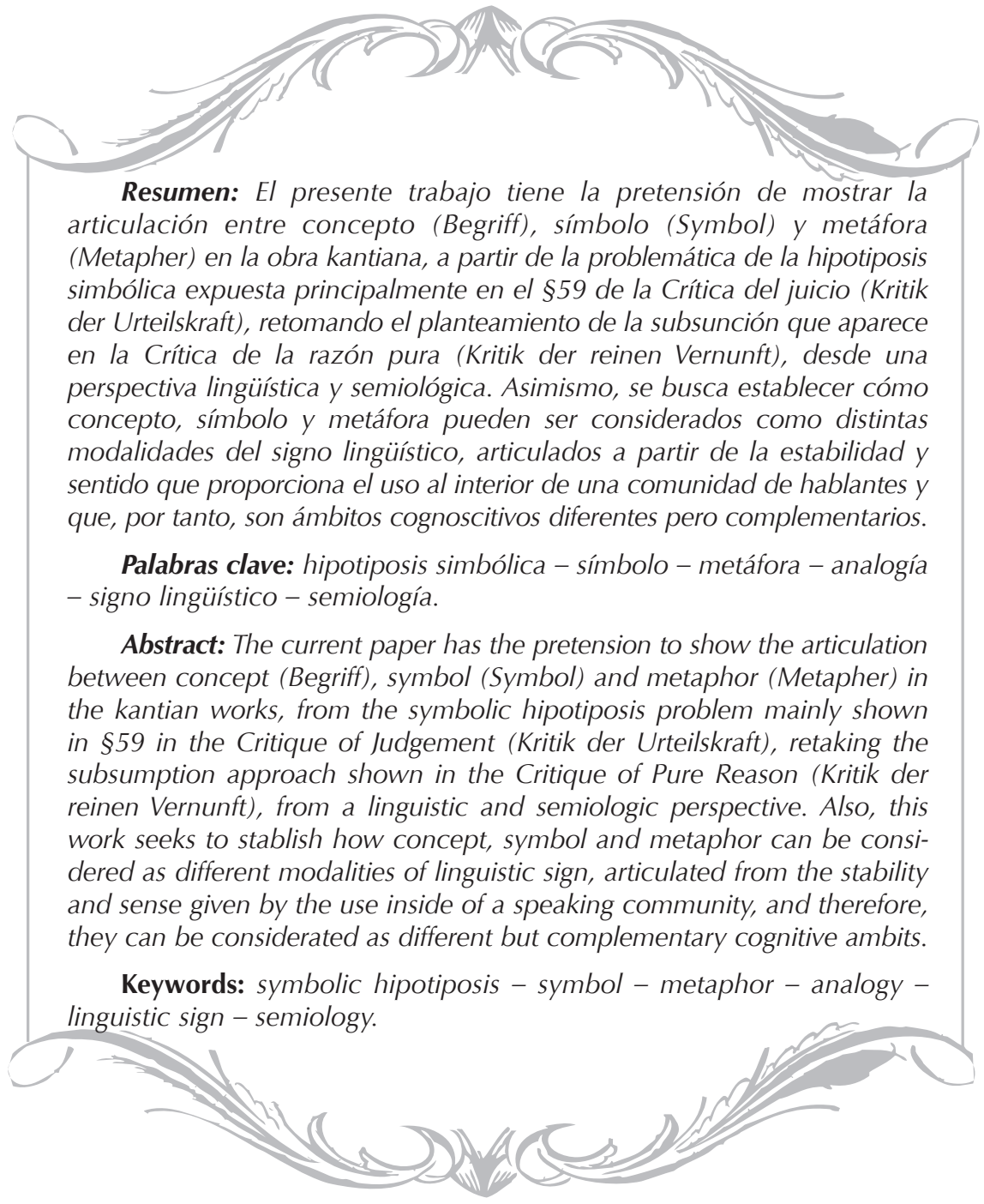


En el §59 de la Crítica del juicio (Kritik der Urteilskraft), Kant desarrolla el proceso a través del cual surge el símbolo (Symbol). Ello obedece a que, de acuerdo con la tabla de la división del concepto de la Nada (Nichts) expuesta en la Crítica de la razón pura (Kritik der reinen Vernunft), ${ }^{1}$ existen ciertos momentos del proceso cognoscitivo en que el encuentro entre intuición (Intuition) y concepto (Begriff) no se da. El símbolo podría situarse dentro de esta tabla como un ens rationis: concepto vacío sin objeto; o mejor dicho, al ser un producto del entendimiento puro, carece de una intuición empírica en la cual se refleje el contenido del mismo, ${ }^{2}$ aunque Kant no lo plantea de manera explícita en ningún punto de las dos obras.

Para dar cuenta de la problemática de este parágrafo, se hace necesario partir de que el entendimiento es para Kant una facultad no sensible de conocimiento, productora de conocimiento discursivo y conceptual. Media entre la razón y la sensibilidad a través de los esquemas (Schema), mismos que posibilitan la aplicación de conceptos (Begriff) a los objetos (Objekts). ${ }^{3}$ La esquematización es, según Kant, un procedimiento que suministra la imagen al concepto; ${ }^{4}$ una representación (Darstellung) trascendental mediadora y pura, porque su origen no es empírico, pero debe ser aplicable al contenido en la representación empírica. En el concepto, el entendimiento opera ordenando representaciones múltiples bajo una común, ${ }^{5}$ subsumiendo una imagen (Bild) proporcionada por la imaginación bajo el concepto correspondiente, ya que este solo se refiere a la representación del objeto, no a su intuición. De aquí procede la facultad del juicio (Vermögen $z u$ urtheilen $)^{6}$ como conocimiento mediato del objeto, es representación de representación.

Pero, dada la separación entre la fuente de donde se origina el objeto y el concepto, respectivamente, ¿cómo es posible que el entendimiento ejecute una síntesis entre ambos? A ello Kant responde con el esquematismo o la subsunción; pero esta se da partiendo del supuesto de la necesidad de existencia de una cierta homogeneidad entre concepto y objeto: el concepto debe contener algo que se encuentre en el objeto, debe existir una influencia del segundo sobre el primero que motive la relación entre ambos y posibilite la correspondencia de la imagen, pese a que Kant, de acuerdo con Adorno, es consciente de que la separación postulada entre la fuente del concepto y el objeto es arbitraria. ${ }^{7}$ Para que el entendimiento esquematice las intuiciones y las "reúna" en un concepto, proporcionándole a este 
imágenes a través de la subsunción de las representaciones empíricas, requiere -siguiendo el análisis de Adorno respecto de la primera Crítica- que las representaciones constituidas en objetos carezcan de cualidades y determinaciones en sí mismas, y por tanto sea moldeable por las formas a priori de la sensibilidad. ${ }^{8}$ Por ello, es un problema el explicar cómo pueden formularse juicios con contenidos que el mero concepto no alcanza a definir, cómo es posible que el enunciar vaya más allá del mero conceptualizar representaciones:

[Respecto del Juicio de la naturaleza] allí donde la experiencia establece una conformidad a leyes en cosas que el concepto general de lo sensible no alcanza ya a entender o a explicar, allí donde el Juicio no puede sacar de sí mismo un principio en relación de la cosa natural con lo suprasensible incognoscible, aunque sólo debe emplearlo con respecto a sí mismo para el conocimiento de la naturaleza, allí puede y debe ser aplicado, desde luego, algún principio a priori, y serlo para el conocimiento de los seres del mundo, abriendo al mismo tiempo para la razón práctica ventajosas respectivas; pero no tiene relación alguna inmediata con el sentimiento del placer y dolor, que es justamente lo enigmático en el principio del Juicio. ${ }^{9}$

Para Kant, el problema de la facultad de juzgar reside en que la misma da cuenta no solo de la subsunción de la representación (Vorstellung) en el concepto al enunciarlo, sino que está en la capacidad de enunciar de algo más, de situarse más allá de la esfera empírica. Pero el demostrar lógicamente la estructura de la actividad del juicio no es posible, porque el juicio es algo que se ejerce $y$, por tanto, no puede demostrarse conceptualmente. No se trata de una mera operación mecánica, de aplicación del concepto a una cosa, sino de intentar dar cuenta cómo la experiencia única e individual de ciertos aspectos de lo nouménico puede ser aprehendida bajo una unidad que pueda dar cuenta de esta singularidad. ${ }^{10}$ Así, pues, ¿cómo es posible explicar la relación del lenguaje con el ámbito ultra-fenoménico?

Es por ello que el presente trabajo está encaminado a exponer la relación y articulación de las ideas de concepto, símbolo y metáfora en la obra kantiana, girando principalmente en torno al §59 de la Crítica del juicio, desde una perspectiva lingüística y semiológica como la de Ferdinand de Saussure y Charles Peirce, para mostrar cómo el concepto se funda sobre el símbolo y la metáfora, ambas contempladas como estructuras lingüísticas de 
carácter social, previas al orden y la esquematización que supone el nombrar objetos, y cómo los tres son así una articulación de dos modos diferentes de concebir el mundo.

\section{II- La hipotiposis esquemática y simbólica}

Para el caso de los conceptos (Begriff) que se originan a raíz de la síntesis de la experiencia posible en el entendimiento, el proporcionarles una imagen más o menos adecuada no es para Kant un problema tan complejo como el del símbolo (Symbol). El símbolo, en tanto que producto puro del entendimiento carente de objeto intuitivo, es lo que permite dar cuenta de aquello que está más allá del conocimiento fenoménico: lo nouménico (Noumenon). El problema del símbolo aparece en Kant al intentar dar cuenta de qué es lo bello, y por qué lo bello es símbolo del bien moral. ${ }^{11}$ ¿Cómo puede el entendi- miento proporcionar una imagen (Bild) adecuada al símbolo, si este no procede de ninguna experiencia (Erfahrung) empírica? Para abordar la temática de la subsunción ya iniciada en la primera Crítica, Kant hace uso del término hipotiposis o "exposición, subjectio sub adspectum", ${ }^{12}$ en lugar del "subsumir".

En el segundo párrafo del $\$ 59$ de la tercera Crítica, Kant define el concepto de hipotiposis como regla a partir de la cual el entendimiento sensibiliza al concepto, proporcionándole una imagen que procede de la intuición, misma que parte de la experiencia sensible:

Toda hipotiposis (exposición, subjectio sub adspectum), como sensibilización, es doble: o esquemática, cuando a un concepto que el entendimiento comprende es dada a priori la intuición correspondiente, o simbólica, cuando bajo un concepto que sólo la razón puede pensar, y del cual bajo ninguna intuición sensible adecuada puede darse, se pone una intuición en la cual solamente el proceder del Juicio es análogo al que observa en el esquematizar, es decir, que concuerda con él sólo según la regla de ese proceder y no según la intuición misma; por lo tanto, sólo según la forma de la reflexión y no según el contenido. ${ }^{13}$

Dado que el símbolo no tiene en sí mismo una imagen que le corresponda porque es un concepto puro, el proceso de hipotiposis simbólica debe proceder análoga- mente al esquematismo, es decir, subsumir intuiciones sensibles bajo el concepto, sin que estas pertenezcan realmente o tengan correspondencia alguna con dicho concepto. 
La imaginación (Einbildungskraft) procede en este punto por asociación, y la subsunción, en este sentido, podría considerarse hasta cierto punto arbitraria. La visibiliza- ción del símbolo, ya sea a través de la palabra o de signos, es una mera expresión indirecta de su contenido -son "meras expresiones"14-, pero no refleja al concepto en sí mismo:

Así, las palabras fundamento (apoyo, base), depender (estar mantenido por arriba), fluir de (en lugar de seguirse), sustancia (lo que lleva los accidentes según se expresa Locke) e innumerables más, no son esquemáticas, sino simbólicas hipotiposis y expresiones para conceptos, no por medio de una intuición directa, sino sólo según la analogía con la misma, es decir, el transporte de la reflexión, sobre un objeto de la intuición, a otro concepto totalmente distinto, al cual quizá no pueda jamás corresponder directamente una intuición. ${ }^{15}$

En este sentido, tanto el símbolo como el concepto tienen la función de "cristalizar" una infinidad de representaciones (Darstellungen) sensibles e intelectuales bajo un solo concepto, constituyéndolo como objeto. Pero más que convertirlo en objeto con carácter de acabado definitivamente, posibilitan que este continúe cambiando y teniendo múltiples $\operatorname{aristas}^{16}$. El conceptualizar los objetos sirve para hacerlos accesibles al intelecto, pero también es otro modo de darles una existencia propia: lo que antes aparecía como una variedad de representaciones heterogéneas, ahora se aparece bajo una unidad, pero el interior de la misma continúa en perpetuo cambio y le dan al concepto su dinamismo, como bien enfatizarán Ferdinand de Saussure y Charles Peirce ya bien entrado el siglo XIX.

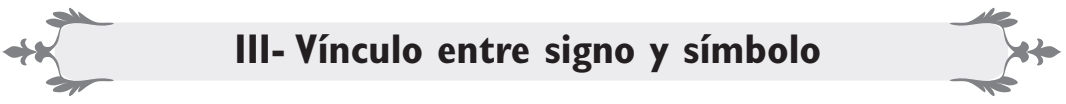

En este punto es menester dar cuenta del signo. Para Kant, el signo (Zeichen) tiene la función de designar de manera sensible al concepto, esto es, tornarlo físico al enunciarlo; o dicho de otro modo, en este reside la posibilidad de comunicar lo que está contenido dentro de la representación, ${ }^{17}$ y puede, por tanto, dar cuenta de contenidos esquemáticos (Schematische) y sim- bólicos (Symbolische). Por otro lado, dentro del signo se hace patente la subsunción de una cantidad indeterminada de representaciones bajo un concepto, subsunción misma que tiene carácter arbitrario y a la vez consensuado; ${ }^{18}$ es decir que el contenido a subsumir o esquematizar en el concepto es proporcionado por la comunidad hablante y no es el mismo de una cultura a otra, ${ }^{19}$ 
dado que es imposible, a partir de la variedad de experiencias empíricas, fijar un contenido determinado a un concepto. El signo y el contenido del mismo, entonces, son para Kant simples juegos de reglas para enunciar juicios, su ámbito es puramente discursivo pero no cognoscitivo (no produce conocimiento, solo lo hacen patente a través de la expresión verbal, gestual, etc.). Sin embargo, Peirce considera que el pensamiento mismo se constituye por signos, y que solo a través del signo puede darse un proceso cognoscitivo. El pensamiento que no se estructura mediante signos no puede conocerse. $^{20}$

Saussure ahondó más en el carácter social y la movilidad del signo que en su carácter de medio cognoscitivo. Primariamente, más que un mero acto de enunciación, el signo tiene la función de comunicar un contenido. Saussure reemplazó la categoría "concepto" por "signo" para construir una unidad desplegable en dos partes: "Y proponemos conservar la palabra signo para designar el conjunto, y reemplazar concepto e imagen acústica respectivamente con significado y significante" ${ }^{\prime 21}$ El signo es entonces esa unidad bajo la cual, siguiendo el esquema kantiano, el entendimiento subsume una imagen (para el caso, una imagen acústica) bajo un concepto. ${ }^{22}$ Tanto el significado como el significante tienen un carácter de tipo social y son por tanto arbitrarios, es decir que no poseen un nexo natural que los vincule a los objetos (sean de tipo empírico o intelectual) que enuncien, pero el nexo que establecen entre las palabras y las cosas se basa en el interés que posea la comunidad hablante que hace uso de determinados conceptos. ${ }^{23} \mathrm{El}$ signo per se no impone un contenido propio porque no tiene similaridad alguna a lo que se remite, solamente remite a algo, ${ }^{24}$ cuyo contenido ha sido fijado por el tiempo y el uso. Asimismo, la palabra no es solo signo, hay en ella algo de copiado, de relación con la cosa, pero esto no equivale a una mímesis. ${ }^{25}$

El concepto y la imagen acústica, o concepto y objeto, dentro de la sociedad están vinculados a la lengua, y es esta, según Saussure, la que da una cierta estabilidad sin excluir la arbitrariedad intrínseca al signo lingüístico. Es decir que es arbitrario porque el signo como unidad carece de nexo con las cosas, pero es impuesto porque los sujetos que nacen y viven dentro de una sociedad determinada no tienen la libertad de cambiar a voluntad un signo o los contenidos del mismo. ${ }^{26}$ Pero es también este aspecto de imposición de la lengua el que no solamente contribuye a dar fijeza al signo y su contenido (por ejemplo, que se use el concepto "perro", para referirse a la imagen de un canino domesticado, de cuatro patas, y no por ejemplo, el concepto "caballo"), sino que reflejan una continuidad del uso de determinados signos a lo largo del tiempo. Tanto la 
lengua como el signo lingüístico están vinculados al tiempo, de acuerdo con Saussure: "Si la lengua tiene carácter de fijeza, no es sólo porque esté ligada a la gravitación de la colectividad, sino también porque está situada en el tiempo" ${ }^{27}$ El tiempo es lo que contribuye a organizar los esquemas de la experiencia sensible, es con el tiempo que la subsunción puede darse porque es el factor común al concepto y la intuición: ${ }^{28}$ tanto el concepto, al ser pensado o vocalizado, como la imagen o significante se desenvuelven en el tiempo y tienen una extensión, es decir que constituyen una línea. ${ }^{29}$

El signo (Zeichen) puede considerarse como una figura lingüística limitada a ser el modo a través del cual se expresa el contenido del concepto a través de la enunciación del concepto mismo. Sin embargo, pensadores como Saussure y Peirce consideran que el símbolo y el signo están íntimamente ligados: el símbolo (Symbol) es un tipo de signo cuyo contenido es un tipo de presentación indirecto, pero también intuitivo. $\mathrm{O}$ mejor dicho, la dinámica del signo o el símbolo están determinadas por el contenido que representan. ${ }^{30} \mathrm{La}$ relación del lenguaje con el símbolo es distinta de la que tiene respecto del concepto. Como indica Ernst Cassirer, la representación de los objetos va más allá del mero asignar nombres a las cosas: tiene que ver con toda una construcción de los mismos. ${ }^{31}$ El lenguaje es lo que media entre el hombre y las cosas, pero lo hace de tal modo que cuando el primero habla no solamente denota al objeto y lo construye en el acto de enunciarlo, sino que también da cuenta de la forma en la que su propia mentalidad está constituida culturalmente. El propio Cassirer señala que el uso de símbolos tiene que ver con el hecho de que hay determinadas situaciones en las que el intelecto falla en su intento por aprehender la realidad conceptualmente, ${ }^{32}$ por lo que la figura del símbolo es mediadora entre la realidad y el sujeto que intenta aprehenderla. Sin embargo, el acto de enunciación, tanto del concepto como del símbolo, si bien es cierto sintetizan una gran variedad de experiencias empíricas o psicológicas, se ve en el defecto de no poder expresar toda la riqueza sensible y "espiritual" que la realidad posee.

El problema del símbolo para Kant deviene del hecho de que el intelecto solo pueda tener experiencia de fenómenos, y por tanto no tiene posibilidad de dar cuenta conceptualmente de las experiencias (Erfahrung) de tipo espiritual, religiosa y psicológica porque sobrepasan el campo de las experiencias empíricas, porque no producen afecciones directamente físicas en el sujeto. Este tipo de experiencias, por decirlo de alguna manera, son las que pertenecen al ámbito de lo nouménico, y es aquí donde el símbolo y la metáfora (Metapher) son requeridas, al ser más efectivas que el concepto en poder dar cuen- 
ta de todo aquello que este no puede. Siguiendo a Ernst Cassirer, bien podría decirse que el símbolo y la metáfora se forman y toman fuerza en etapas del desarroIlo humano que son netamente pre-conceptuales. Según Cassirer, estas etapas "caracterízanse precisamente por el hecho de que aún no se ha establecido la franca separación entre 'fantasía' y 'realidad', entre 'imagen' y 'cosa', entre 'lo representado' y 'lo real'". ${ }^{33}$ De ahí que el símbolo sea un signo mucho más maleable que el concepto y tenga una mayor vinculación con el contenido que denota.

Una de las hipótesis que podrían sustentar esta postura es la de Herder respecto al origen del lenguaje: El verbo es lo primero que el hombre enuncia, porque lo que siente y escucha son relaciones, actos. ${ }^{34}$ El oído es para Herder el sentido que tiene primacía en la creación del lenguaje, porque el sonido del entorno penetra en la mente del sujeto y deja una marca característica. A partir de lo que el sujeto escucha, pasa a intentar dar un nombre a ese acto. El nombre surge en una etapa posterior al verbo, como una manera más abstracta de dar cuenta de la variedad de sensaciones que el hombre experimenta en su vida cotidiana. De ahí que el símbolo y la metáfora puedan considerarse como fruto de la necesidad, del impulso del ser humano de hablar en un momento en el cual aún no hay un ordenamiento conceptual del mundo. ${ }^{35} \mathrm{~A}$ partir del concepto se inicia, por así decirlo, un proceso de orden en el caos de representaciones que supone el mundo exterior.

Peirce consideraba al símbolo como signos generales, dado que su significado o contenido era otorgado por el uso. En su raíz, la palabra símbolo significa "arrojar junto", o también "contrato o convención". ${ }^{36}$ Asimismo, la conexión entre el objeto y el símbolo es otorgada por el sujeto o la comunidad que hace uso del mismo; sin embargo, a este respecto Saussure considera al símbolo como una clase de signo cuya existencia reside en el significante $o$ imagen que posee un concepto. A diferencia del signo, que se construye con un concepto y una imagen, el símbolo no es completamente arbitrario: existe una suerte de vínculo natural entre símbolo y el juego de imágenes que encierra; así, Saussure pone de ejemplo: "El símbolo de la justicia, la balanza, no podría reemplazarse por otro objeto cualquiera, un carro, por ejemplo". ${ }^{37}$ Pero el que un símbolo perdure con el paso del tiempo, en el sentido de que el mismo esté ligado a la imagen que designa, tiene que ver también con la estabilidad que el uso le otorga. ${ }^{38}$ El vínculo entre significado y significante es en realidad inmotivado, y por ello puede considerarse arbitrario; pero su perdurabilidad dentro la comunidad que hace uso de este es lo que hace que la representación que exhibe el símbolo se torne en cierta medida natural. 


\section{a) El símbolo y la analogía}

Ahora, es pertinente también analizar la relación que existe entre el símbolo (Symbol) y la analogía (Analogie). Cuando Kant da cuenta del proceder de la hipotiposis simbólica, pone un especial énfasis en el concepto de analogía: "Se pone una intuición en la cual solamente el proceder del Juicio es análogo al que observa en el esquematizar, es decir, que concuerda con él sólo según la regla de ese proceder y no según la intuición misma; por lo tanto, sólo según la forma de la reflexión y no según el contenido" ${ }^{39}$ Ello se debe a que dado que el símbolo obtiene su contenido a través de la subsunción de imágenes -que no le corresponden directamente, porque no hay representaciones que se "ajusten" al contenido del símbolo, al ser este un concepto puro de la razón- por medio de una asociación realizada por la imaginación, el objeto que exhibe es un objeto indirecto de su idea, es decir que el conocimiento que otorga un símbolo es una analogía ${ }^{40}$ del contenido que intenta exhibir (Darstellen). Kant define la analogía en la primera Crítica como una regla a partir de la cual el intelecto conoce determinados objetos que no son dados a la experiencia (Noumena). La analogía, entonces, procede a través de la relación entre determinados objetos para dar una imagen al objeto que no puede conocer:

Pero en filosofía la analogía no es igualdad de dos relaciones cuantitativas, sino [de dos relaciones] cualitativas, en la cual, a partir de tres miembros dados sólo puedo conocer y dar a priori la relación con un cuarto, pero no este cuarto miembro mismo; aunque tengo, por cierto, una regla para buscarlo en la experiencia, y una señal para encontrarlo en ella. Una analogía de la experiencia será, entonces, sólo una regla según la cual, de las percepciones, ha de surgir la unidad de la experiencia (no como [si fuera] ella misma una percepción, [entendida] como intuición empírica en general); y como principio valdrá para los objetos (para los fenómenos) no constitutivamente, sino sólo regulativamente. ${ }^{41}$

Siguiendo esta misma línea, Peirce también enfatiza en que el símbolo no denota cualquier cosa, sino un tipo determinado de cosas. Es decir que no cualquier cosa pue- de ser el contenido de un símbolo, porque este es en sí mismo un tipo de objeto. ${ }^{42}$ De ahí que las imágenes que se subsuman bajo un símbolo deban ser dadas por analogía 
o semejanza, porque no existe una que pueda ser adecuada al objeto sui generis que es el símbolo.

\section{b) El símbolo y la metáfora}

La metáfora (Metapher) y el símbolo (Symbol) coinciden en una relación de semejanza, ${ }^{43}$ en tanto que ambos se relacionan con las representaciones que designan de manera arbitraria. Haciendo un breve retroceso al problema del origen del lenguaje -vinculado al origen del símbolo-, puede verse, de acuerdo con Cassirer, que la metáfora se origina paralelamente con el desarrollo del lenguaje mismo, estrechamente vinculado al pensamiento mítico. ${ }^{44}$ La metáfora, podría decirse, tiene por función el articular relaciones entre dominios conceptuales, ${ }^{45}$ es decir que hace una exhibición (Darstellung) de un concepto desde un dominio completamente diferente (un ejemplo podría ser el que usa Kant para referirse al Estado: "Así, un estado monárquico que esté regido por leyes populares internas es representado por un cuerpo animado; por una simple máquina [como, verbigracia, por un molinillo] cuando es regido por una voluntad única absoluta"46), atribuyendo así un significado distinto al contenido de la metáfora usada. La metáfora se estructura sobre proyecciones, es decir, correspondencias que enlazan los dominios conceptuales de los que hacen uso cuando son enunciadas.
Al igual que el símbolo, al proceder en su construcción a través de la analogía y la subsunción de una serie de experiencias bajo determinados conceptos, la metáfora "constituye un mecanismo para comprender y expresar situaciones complejas sirviéndose de conceptos más básicos y conocidos". ${ }^{47} \mathrm{Al}$ ser ambos construcciones que se estructuran cultural y temporalmente, tienen una cierta fijeza, pero también movilidad de una sociedad a otra, o de una época a otra. Incluso podría decirse que el símbolo y la metáfora están estrechamente vinculados porque el símbolo puede encontrarse al interior de una expresión metafórica, en tanto que ambos muestran indirectamente el contenido de los objetos a los cuales se refieren. Por otro lado, ambos son expresiones y modos de construir realidad, son el paso hacia la enunciación de lo otro que el intelecto no puede dar cuenta a través de la estructura esquemática del entendimiento. Tanto símbolo como metáfora tienen referencia a ámbitos que son netamente intuitivos, y por tanto extremadamente complejos y diversos, pero logran sintetizar esta variedad de sensaciones en unidades que poseen un sentido en sí mismo, sentido que otorga el contexto socio-histórico del sujeto que efectúa la enunciación.

Tanto el símbolo como la metáfora no son solo modalidades del juicio, sino que también 
son condiciones de posibilidad del mismo, pues sobre ambos se funda la hipotiposis esquemática que caracteriza al concepto. A la base, tanto concepto como símbolo y metáfora, tienen una síntesis de experiencias sensibles que aprehende la "esencia" de la experiencia empírica y la concentra bajo una unidad y le otorga una realidad, ya que lo que no es nombrado no tiene una existencia fáctica dentro del lenguaje. ${ }^{48} \mathrm{EI}$ sentido que posea esta unidad está también en estrecha relación con las conexiones que tiene con otros conceptos, otros símbolos o expre- siones metafóricas, va más allá del mero denotar.

Así, pues, el símbolo y la metáfora no solamente permiten establecer una conexión con el campo nouménico de la realidad, permitiendo al hombre hablar de aquello que no puede ser conceptualizado por ir más allá de la razón, sino que también son modos de esquematizar la realidad y la experiencia del mundo, tornándola más rica y amplia. Sin embargo, es otro tipo de esquematismo, de apropiación del entorno. Son otros modos de pensar y de situarse en la realidad.

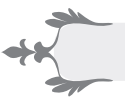

V- Conclusiones
El concepto (Begriff) y el símbolo (Symbol) son estructuras de exhibición (Darstellung) de la realidad, ambos operan de maneras similares, por hipotiposis esquemática y simbólica respectivamente. Para mostrar un contenido, subsumen imágenes obtenidas de la experiencia empírica de acuerdo a una regla de correspondencia. Sin embargo, el problema kantiano reside en que el símbolo es un producto del entendimiento puro, por tanto, carece de intuiciones empíricas que se le adecuen. La problemática del símbolo se basa a su vez en el carácter de mediador que tiene el símbolo al interior de la facultad de juzgar (Vermögen zu urtheilen), porque no media solo con una experiencia empírica, sino con una de tipo nouménico. Ahora, al tratar el símbolo con contenidos de tipo ultra-fenoménico, es para Kant una dificultad demostrar conceptualmente cómo el intelecto opera para proporcionar imágenes a un contenido que no está relacionado con concreciones, como lo hace el concepto.

El proceso de hipotiposis está, por así decirlo, montado en el ámbito de la convención y el uso lingüístico que le otorgan no solo la estabilidad que hace que un concepto o un símbolo permanezcan más o menos fijos con el paso del tiempo, sino que le proporcionan también la arbitrariedad y libertad suficiente para establecer nexos entre imágenes (Bild) y signos (Zeichen) que no tienen un vínculo natural entre sí. Ni el concepto ni el símbolo, ni la metáfora (Metapher) 
operan por mímesis respecto de la realidad, porque, siguiendo a Kant, la realidad que el sujeto percibe ya está mediada y no está en puridad. No existen en los objetos ni en las experiencias algún indicador del nombre que poseen y cuáles son sus contenidos. El lenguaje es una estructura que esquematiza la realidad porque otorga nombres, establece relaciones de fijeza, movilidad y sentido entre fenómenos y noúmenos.

Tanto concepto, como símbolo y metáfora son tres aspectos diferentes del signo lingüístico, y más allá de tener una función denotativa, configuran espacios de conocimiento de lo real en tanto que proporcionan ciertas regularidades a las percepciones humanas. El símbolo y la metáfora son ámbitos lingüísticos que funcionan a través de una exhibición (Darstellung) indirecta de su objeto, por ello proceden por analogía (Analogie) para proporcionar un juego de imágenes a su contenido.
Esto obedece a que su formación es de tipo pre-conceptual, es decir que nacen como estructuras de ordenamiento que primariamente captan relaciones y procesos que son experimentados y realmente sentidos por el hombre, como lo muestra el pensamiento mítico. Son abstracciones que poseen un contenido intuitivo amplio, pero que se ha ido concentrado y fijando paulatinamente gracias a la tradición de la sociedad que hace uso de ellos.

El concepto procura una esquematización más precisa y concreta de los fenómenos sensibles al exhibirlos, pero también el símbolo y la metáfora tienen una efectividad sobre la realidad: es a través de ellos que el ser humano continúa dando cuenta de aquello que está más allá del saber científico y que no puede ser nombrado por medio de conceptos. Metáfora y símbolo establecen órdenes distintos de realidad, son un paso a otros modos de pensar lo real.

\section{Bibliografía}

\section{Fuentes primarias}

os Kant, Immanuel, Antropología en sentido pragmático, Traducción de José Gaos, Siglo XXI Editores, Madrid, 1991.

os Kant, Immanuel, Crítica del juicio, Edición y traducción de Manuel García Morente, Espasa Calpe, Madrid, 2001.

os Kant, Immanuel, Crítica de la razón pura, Traducción, estudio y notas de Mario Caimi, FCE, UAM, UNAM. México, 1ª ed., 2009. 


\section{Fuentes secundarias}

os Adorno, Theodor, Kant's Critique of Pure Reason, edited by Rolf Tiedemann, translated by Rodney Livingstone, Stanford University Press, California, 2001.

os Barthes, Roland, Elementos de Semiología, traducción de Alberto Méndez, Alberto Corazón Editor, Madrid, 1971.

os Blumenberg, Hans, Paradigms for a Metaphorology, translated by Robert Savage, Cornell University Press and Cornell University Library, New York, 2010.

os Caimi, Mario, La metafísica de Kant, Eudeba, Buenos Aires, 1ª ed., 1989.

os Cuenca, Maria Josep, Hilferty, Joseph, Introducción a la lingüística cognitiva, Editorial Ariel, Barcelona, 2007.

os Cassirer, Ernst, Filosofía de las formas simbólicas, I. El lenguaje, FCE, México, 1971.

os Cassirer, Ernst, Language and Myth, translated, with preface by Susanne K. Langer, Harper \& Row, New York, 1946.

os Cassirer, Ernst, Sechehaye, A., et al., Teoría del lenguaje y lingüística general, Paidós, Buenos Aires, $3^{\text {a }}$ ed, 1972.

os Gadamer, Hans-Georg, Verdad y Método (vol. I), Ediciones Sígueme, Salamanca, 8a ed., 1999.

os Jakobson, Roman, Halle, Morris, Fundamentos del Lenguaje, traducción de Carlos Piera, Editorial Ayuso y Editorial Pluma, España, 3ª ed., 1980.

os Leach, Edmund, Lógica y comunicación. La lógica de la conexión de los símbolos, Siglo XXI Editores, España, 1989.

os Lévi-Strauss, Claude, Antropología Estructural, traducción de Eliseo Verón, Paidós, Barcelona, 1995.

os Martínez Marzoa, Felipe, Desconocida raíz común, Antonio Machado Libros S.A., Madrid, 1987.

os Martínez Marzoa, Felipe, Releer a Kant, Editorial Anthropos, Barcelona, 1989.

os Saussure, Ferdinand de, Curso de Lingüística General, traducción, prólogo y notas de Amado Alonso, Editorial Losada, Buenos Aires, $24^{\mathrm{a}}$ ed., 1945. 


\section{Diccionarios}

os Vox: Diccionario Ilustrado Latino-Español, prólogo de don Vicente García de Diego, Bibliograf, España, 19ª ed., 1988.

us Vox: Diccionario Manual Griego-Español, prólogo de José Manuel Pabón Suárez de Urbina, Vox, Barcelona, 1967.

\section{Documentos en línea}

os http://www.marxists.org/archive/herder/1772/origins-language.htm

os http://www.cspeirce.com/menu/library/bycsp/bycsp.htm

\section{Notas}

1 Cf. Kant, Immanuel, Crítica de la razón pura, trad., estudio y notas de Mario Caimi, FCE, UAM, UNAM. México, $1^{a}$ ed., 2009, A290/292-B346/349.

2 Cf. Ibid, A290/291-B347.

3 Cf. Ibid, A138-b177.

4 Cf. Ibid, A140-B179/180.

5 Cf. Ibid, A68-B93.

6 A este respecto, Kant define la facultad de juzgar como "la facultad de subsumir bajo reglas, es decir, de discernir si algo está, o no, bajo una regla dada (casus datae legis)". Ibid, A132-B171.

7 Cf. Adorno, Theodor, Kant's Critique of Pure Reason, edited by Rolf Tiedemann, translated by Rodney Livingstone, Stanford University Press, California, 2001, p. 132.

8 Sin embargo, señala Adorno que esta misma plasticidad de la representación es solo un supuesto, pero no está planteada de modo explícito en la obra kantiana, aunque es plausible considerar que esta carencia de determinaciones posibilita la síntesis entre objetos y conceptos a pesar de que ambos tienen, según Kant, orígenes distintos. Cf. Ibid, p. 98.
9 Kant, Immanuel, Crítica del juicio, edición y traducción de Manuel García Morente, Espasa Calpe, Madrid, 2001, p. 92 .

10 Cf. Gadamer, Hans-Georg, Verdad y Método (vol. I), Ediciones Sígueme, Salamanca, 8a ed., 1999, p. 62.

11 Cf. Kant, Immanuel, Crítica del juicio, op. cit., \$59, p. 319.

12 Cf. Kant, Immanuel, Crítica del juicio, op. cit., \$59, p. 317.

13 Cf. Ibid, \$59, p. 317.

14 Cf. Ibid, \$59, p. 318.

15 Cf. Ibid, \$59, pp. 318-319.

16 Cf. Cassirer, Ernst, "El lenguaje y la construcción del mundo de los objetos", en Cassirer, Ernst, Sechehaye, A., et al., Teoría del lenguaje y lingüistica general, Paidós, Buenos Aires, $3^{\text {a }}$ ed., 1972, p. 26.

17 "Es de notar que, de un modo inconcebible para nosotros, sabe la imaginación, no sólo volver a llamar a sí los signos de conceptos, incluso de mucho tiempo acá, sino también reproducir la imagen y la figura del objeto, sacada de inexpresable número de objetos de diferentes clases o de una y la misma clase; y más aún, 
por decirlo así, una imagen encima de otra, realmente, según toda presunción, aunque no con suficiente consciencia, y de la congruencia de muchas de la misma clase sacar un término medio que sirva a todas de común medida." Kant, Immanuel, Crítica del juicio, op. cit., \17, p. 170.

19 A este respecto, Kant ejemplifica con la idea de "hombre bello": "Pues cuando, de la misma manera, se ha buscado la cabeza media, y así sucesivamente, la figura que sale está a la base de la idea normal del hombre bello en el país donde se ha establecido esa comparación; de aquí que un negro deba tener necesariamente, bajo esas condiciones empíricas, otra idea normal de la belleza de la figura que un blanco, y un chino otra que un europeo". Ibid, \$17, p. 171.

20 Cf. Peirce, Charles S., Questions Concerning Certain Faculties Claimed for Man. Versión en línea: http://www.cspeirce. $\mathrm{com} / \mathrm{menu} /$ library/bycsp/question/ qu-frame.htm

21 Cf. Saussure, Ferdinand de, Curso de Lingüistica General, Traducción, prólogo y notas de Amado Alonso, Editorial Losada, Buenos Aires, 24ª ed., 1945, p. 93.

22 Aunque con Kant no se especifica si esa imagen que proporciona la hipotiposis al concepto es de tipo visual o auditivo.

23 Cito aquí a Gadamer: "La articulación de palabras y cosas, que emprende cada lengua a su manera, representa en todas partes una primera conceptuación natural muy lejana al sistema de la conceptuación científica. Se guía por entero según el aspecto humano de las cosas, según el sistema de sus necesidades e intereses. Lo que para una comunidad lingüística es esencial para cierta cosa, puede reunir a ésta con otras cosas por lo demás completamente distintas bajo la unidad de una denominación, con sólo que todas ellas posean este mismo aspecto esencial. La denominación (impositio nominis) no responde en modo alguno a los conceptos esenciales de la ciencia y a su sistema clasificatorio de géneros y especies." Gadamer, Hans-Georg, Verdad y Método (vol. I), op. cit., p. 522.

24 Cf. Ibid, pp. 495-496.

25 Cf. Ibid, p. 500.

26 Cf. Saussure, Ferdinand de, Curso de Lingüística General, op. cit., p. 100.

27 Cf. Ibid.

28 Cf. Adorno, Theodor, Kant's Critique of Pure Reason, op. cit., p. 133.

29 Cf. Saussure, Ferdinand de, Curso de Lingüistica General, op. cit., p. 95.

$30 \mathrm{Al}$ respecto, señala Peirce: "We may distinguish between different kinds of signs according to the relation between their material and imputed qualities. There are some signs whose imputed qualities are derived from and similar to their material ones such as a picture. The colors of a landscape are not, it is true, the same as those of nature. They do not make a match but they are sufficiently like them to suggest immediately to the mind the appearance intended to be represented. In other cases the connection is a purely conventional one, as in the case of most words. In the third class of cases the connection is owing to natural causation. It cannot be said to be merely conventional - still, there is no resemblance. If I point my finger to an object in order to distinguish it, there is no resemblance between my finger and the object, but I imitate the effect of an attractive force applied to the finger, 
which naturally carries the thoughts of the person whom I am addressing towards the object pointed out." Peirce, Charles S., On Representations.

Versión en línea: http://www.cspeirce.com/menu/library/bycsp/logic/ ms212.htm

31 Cf. Cassirer, Ernst, Teoría del lenguaje y lingüistica general, op. cit., p. 23.

32 Cf. Cassirer, Ernst, Language and Myth, translated, with preface by Susanne K. Langer, Harper \& Row, New York, 1946, p. 7.

33 Cassirer, Ernst, Teoría del lenguaje y lingüistica general, op. cit., p. 33.

34 Cito aquí a Herder: "Since the whole of nature resounds, there is nothing more natural for a sensuous human being than that it lives, it speaks, it acts. That savage saw the high tree with its splendid crown and admired. The crown rustled! That is the work of divinity! The savage falls down and prays to it! Behold there the history of the sensuous human being, the obscure link, bow nouns arise from the verbs - and the easiest step to abstraction! (...) One sees his need to express himself so distinctly; one sees it to an ever greater extent the further away in sensation the idea lay from feeling and sound - so that one may no longer doubt the human character of the origin of language." Herder, Johann Gottfried, Treatise on the Origin of Language.

Versión en línea: http://www.marxists. org/archive/herder/1772/originslanguage.htm

35 Cf. Ibid.

36 Cito a Peirce: "It is usually said that in the word symbol, the throwing together is to be understood in the sense of to conjecture; but were that the case, we ought to find that sometimes, at least, it meant a conjecture, a meaning for which literature may be searched in vain. But the Greeks used "throw together" (sumballein) very frequently to signify the making of a contract or convention." Peirce, Charles S., What Is a Sign? Versión en línea: http://www. iupui.edu/ peirce/ep/ep2/ep2book/ ch02/ep2ch2.htm También puede añadirse que el vocablo equivale a "contrato, tratado de comercio; marca, distintivo, señal, signo, contraseña; emblema, símbolo, insignia; presagio, auspicio; convención, tratado". Definición tomada de Vox: Diccionario Manual Griego-Español, prólogo de José Manuel Pabón Suárez de Urbina, Vox, Barcelona, 1967, p. 553.

37 Saussure, Ferdinand de, Curso de Lingüistica General, op. cit., p. 94.

38 Cf. Ibid.

39 Kant, Immanuel, Crítica del juicio, op. cit., \59, p. 317 Las bastardillas son marcado propio.

40 Cf. Caimi, Mario, La metafísica de Kant, Eudeba, Buenos Aires, $1^{a}$ ed., 1989, pp. 80-81. A este respecto, hay que añadir que la analogía implica "proporción, semejanza o concordancia". Definición tomada de Vox: Diccionario Manual Griego-Español, op. cit., p. 42.

41 Kant, Immanuel, Crítica de la raźón pura, op. cit., A179/180-B222/223.

42 Cf. Peirce, Charles S., What is a sign?, op. cit.

43 Cf. Leach, Edmund, Lógica y comunicación. La lógica de la conexión de los símbolos, Siglo XXI Editores, España, 1989, p. 21.

44 Cf. Cassirer, Ernst, Myth and Language, op. cit., p. 84 .

45 Cf. Cuenca, Maria Josep, Hilferty, Joseph, Introducción a la lingüística cognitiva, 
Editorial Ariel, Barcelona, 2007, p. 101. Las metáforas, de acuerdo con Cuenca y Hilferty, son de dos tipos: metáforas conceptuales y expresiones metafóricas. La primera es una agrupación de expresiones metafóricas, mientras que la segunda es el caso individual de una metáfora.

46 Kant, Immanuel, Crítica del juicio, op. cit., \$59, p. 318. Kant, en este ejemplo, más que hacer uso de un símbolo para representar la figura del Estado, hace una proyección o exhibición de conceptos de un dominio de origen de tipo bioló- gico o mecanicista, para aplicarlos en un dominio de destino de tipo político. Siguiendo a Cuenca y Hilferty, en este caso, el tipo de proyección que se efectúa es de correspondencia epistémica, es decir que representan el conocimiento de un dominio, y lo relaciona al importarlo del dominio de origen al de destino.

47 Cuenca, Maria Josep, Hilferty, Joseph, Introducción a la lingüistica cognitiva, op. cit., p. 98.

48 Cf. Cassirer, Ernst, Myth and Language, op. cit., p. 95. 